\title{
SIMULASI DATABASE BEBAN KERJA DOSEN PERGURUAN TINGGI MENGGUNAKAN DIMENSIONAL MODELING
}

\author{
Anisah \\ Program Studi Sistem Informasi \\ STMIK Atma Luhur \\ Email:anisah@atmaluhur.ac.id \\ Yurindra \\ Program Studi Teknik Informatika \\ STMIK Atma Luhur \\ Email: Yurindra@atmaluhur.ac.id \\ Yohanes Setiawan Japriadi \\ Program Studi Teknik Informatika \\ STMIK Atma Luhur \\ Email: ysetiawanj@atmaluhur.ac.id \\ Yuyi Andrika \\ Program Studi Sistem Informasi \\ STMIK Atma Luhur \\ Email: yuyiandrika@atmaluhur.ac.id \\ Harizki Arie Pradana \\ Program Studi Teknik Informatika \\ STMIK Atma Luhur \\ Email: harizkiarieP@atmaluhur.ac.id
}

\begin{abstract}
ABSTRAK
Data warehouse sudah banyak digunakan untuk membantu eksekutif dalam pengambilan sebuah keputusan, diantaranya bidang kesehatan, bidang perhotelan, dan tidak ketinggalan di bidang pendidikan. Akan tetapi, belum banyak yang menggunakan data warehouse khususnya untuk keperluan Beban Kerja Dosen (BKD). Penelitian sebelumnya ada yang melakukan penelitian mengenai BKD, tetapi sebatas perancangan untuk database operasional. Beban kerja dosen haruslah dilakukan evaluasi agar dosen yang ada di perguruan tinggi merupakan dosen yang profesional yang senantiasa menjunjung tinggi pelaksanaan Tri Dharma Perguruan Tinggi. Masalah yang dihadapi saat ini, untuk mendukung proses evaluasi beban kerja dosen dan pengambilan keputusan yang tepat oleh para pemangku kepentingan perguruan tinggi tersebut, belum adanya suatu database beban kerja dosen yang terintegrasi dan terpusat yang bisa diakses oleh pemangku kepentingan perguruan tinggi untuk memperoleh informasi stategis mengenai beban kerja dosen suatu perguruan tinggi secara Iengkap, cepat dan akurat. Adapun tujuan dari penelitian ini adalah merancang data warehouse yang dapat membantu para pemangku kepentingan perguruan tinggi dalam memperoleh informasi stategis mengenai beban kerja dosen tersebut. Metode penelitian yang digunakan pada tahap analisis dan perancangan data warehouse menggunakan Four Step Methodology kimball. Database yang dihasilkan akan dilakukan simulasi dengan menggunakan interface PhpMyadmin untuk kemudian dilakukan evaluasi. Berdasarkan hasil evaluasi, data warehouse beban kerja dosen mampu untuk bisa menghasilkan informasi strategis yang dibutuhkan oleh perguruan tinggi.
\end{abstract}

Kata Kunci: beban kerja dosen; data warehouse; four step design methodology.

\section{ABSTRACT}

Data warehouse has been used widely to help the executives in making decisions, including in the health sector, hospitality sector, and of course education too. However, not many people used data warehouse especially for Lecturer Worksheet (BKD). The Previous studies have conducted research on BKD, but still limited about design for operational databases. The worksheet of lecturers must be evaluated even the lecturers in an institution are professional lecturers who always did the Tri Dharma Perguruan Tinggi. The problem in this study is how to support the process of evaluating the worksheet of 
lecturers and making appropriate decisions by the stakeholders of the higher education, there is no integrated and centralized lecturer worksheet database that can be accessed by stakeholders of the institutions to obtain strategic information about lecturer worksheet of a college is complete, fast and accurate. The purpose of this study is to design a data warehouse that can help university stakeholders in obtaining strategic information about the lecturer worksheet. The research method used in the data warehouse analysis and design stage uses the Four Step Methodology Kimball. The resulting database will be simulated using the PhpMyadmin interface for later evaluation. Based on the results of the evaluation, the lecturer worksheet data warehouse can produce strategic information needed by the institutions.

Keywords: lecturer worksheet; data warehouse; nine step design methodology.

\section{PENDAHULUAN}

Data warehouse sudah banyak digunakan untuk membantu eksekutif dalam pengambilan sebuah keputusan. Sebagai contoh penelitian yang dilakukan oleh Joseph George, dkk pada tahun 2015[10] dengan judul penelitian Data Warehouse Design Considerations for a Healthcare Business Intelligence System. yang melakukan penelitian mengenai data warehouse di bidang kesehatan, dalam penelitian tersebut data warehouse tidak dapat dihilangkan dalam Business Intelligence (BI), terdapat desain sebuah struktur DW yang optimal untuk domain perawatan kesehatan.

Penelitian yang dilakukan oleh Abba Suganda Girsang, dkk: 2017[14] yang melakukan penelitian mengenai data warehouse di bidang perhotelan dengan judul penelitian Decision Support System Using Data Warehouse for Hotel Reservation System. Dalam penelitian tersebut menggunakan metode nine step methodology designed by Kimball and Ross. Dimana data warehouse yang dihasilkan digunakan untuk mengintegrasikan sumber data yang dibutuhkan untuk sistem reservasi hotel sehingga dapat memberikan informasi yang cepat dan akurat.

Penelitian yang dilakukan oleh Reza Rahutomo, dkk:2018[12] mengenai data warehouse di bidang pendidikan dengan judul penelitian Building Datawarehouse for Educational Institutions in 9 Steps. Dalam penelitian tersebut menggunakan metode Nine-step methodology proposed by Kimball. Dalam penelitan tersebut terbentuknya data warehouse yang dapat menampilkan informasi yang berguna untuk dukungan manajemen pendidikan.

Penelitian yang dilakukan oleh I Gede Made Karma, Jeni Susanti, 2015[9] dengan judul penelitian Pengembangan Sistem Informasi Beban Kerja Dosen (BKD) Untuk Pelaporan Pelaksanaan Tridharma Perguruan Tinggi, menggunakan metode berorientasi objek, UML sebagai alat bantu pemodelan. Dalam penelitian tersebut, pembangunan sistem informasi beban kerja dosen dibuat untuk memudahkan staf jurusan untuk melakukan proses pencatatan, pengelolaan dan pelaporan kegiatan Tridharma.

Penelitian yang dilakukan oleh Ganda Wijaya, 2017[11] dengan judul Perancangan Data Warehouse Nilai Mahasiswa Dengan Kimball Nine-Step Methodology. Menggunakan metodologi Kimball nine-step Methodology. Dimana dalam penelitian tersebut data warehouse dapat memberikan ringkasan informasi yang cepat, akurat dan berkesinambungan sehingga dapat membantu manajemen dalam membuat kebijakan untuk masa yang akan datang.

Penelitian yang dilakukan oleh Indrajani Sutedja, dkk, 2018[15] dengan judul Building A Data Warehouse to support Active Student Management: Analysis and Design. Metode yang digunakan adalah Four-Step Methodology used by Ralph Kimball. Penelitian tersebut menghasilkan rancangan data warehouse yang diintegrasikan dari berbagai database operasional yang digunakan untuk memberikan informasi tentang siswa aktif di Universitas $\mathrm{XYZ}$.

Penelitian yang dilakukan oleh Yova Ruldeviyani, dkk, 2016[16] dengan judul Design And Implementation Of Merchant Acquirer Data Warehouse at PT. XYZ. Metode yang digunakan adalah Ralph L. Kimball. Dalam penelitian tersebut menghasilkan rancangan dan implementasi Merchant Acquirer data warehouse di PT.XYZ.

Penelitian Fajar Zaki Al Faris, dkk, 2018[17] dengan judul Development of Data Warehouse to Improve Services in IT Services Company. Menggunakan metode Kimball methodology. Dalam penelitian tersebut menghasilkan data warehouse untuk membantu perusahaan menjaga waktu layanan pengiriman selalu tepat sasaran. Saat ini, belum banyak yang menggunakan data warehouse khusus untuk beban kerja dosen. Seperti penelitian sebelumnya, ada yang meneliti mengenai beban kerja dosen (BKD) akan tetapi sebatas perancangan untuk database operasional, seperti penelitian yang dilakukan oleh Muhammad azhar irwansyah, 2015 dengan judul penelitian sistem informasi repository digital beban kerja dosen yang menggunakan metode SDLC. Dalam penelitian tersebut Sistem informasi repository digital ini dapat memenuhi kebutuhan dosen dalam menyimpan berkas BKD dalam bentuk digital. Aplikasi Repository Digital Beban Kerja Dosen (BKD) dapat membantu dosen yang ingin mengetahui informasi beban kerja yang di tanggung dan membantu pimpinan dalam mengetahui informasi beban kerja yang di tanggung setiap dosen [2]. 
Dosen adalah salah satu komponen esensial dalam suatu sistem pendidikan di perguruan tinggi Sebagaimana diamanatkan dalam UU Nomor 14 Tahun 2005 tentang Guru dan Dosen yang tugas utamanya adalah mentransformasikan, mengembangkan, dan menyebarluaskan ilmu pengetahuan, teknologi, dan seni melalui pendidikan, penelitian, dan pengabdian kepada masyarakat. Tugas utama yang harus dilakukan oleh dosen adalah melaksanakan tridharma perguruan tinggi dengan beban kerja paling sedikit sepadan dengan 12 (dua belas) sks dan paling banyak 16 (enam betas) sks pada setiap semester sesuai dengan kualifikasi akademik. untuk profesor (guru besar) yang merupakan dosen dengan jabatan akademik tertinggi pada satuan pendidikan tinggi mempunyai tugas khusus yaitu menulis buku beserta karya ilmiah dan menyebar luaskan gagasannya untuk mencerahkan masyarakat. Pelaksanaan tugas utama dosen ini perlu dievaluasi dan dilaporkan secara periodik sebagai bentuk akuntabilitas kinerja dosen kepada para pemangku kepentingan. Untuk menjamin pelaksanaan tug as dosen (BKD) berjalan sesuai dengan kriteria yang ditetapkan dalam peraturan perundang undangan maka perlu dievaluasi setiap periode waktu yang ditentukan. (Pedoman BKD, 2012). [1]

Adapun dilakukannya Evaluasi tugas utama dosen dimaksudkan untuk (1) meningkatkan profesionalisme dosen dalam melaksanakan tugas, (2) meningkatkan proses dan hasil pendidikan (3) menilai akuntabilitas kinerja dosen di perguruan tinggi (4) meningkatkan atmosfer akademik di semua jenjang perguruan tinggi dan (5) mempercepat terwujudnya tujuan pendidikan nasional(Pedoman BKD, 2012). [1]

Berdasarkan hal tersebut, tentunya kemudahan para pemangku kepentingan dalam melakukan evaluasi tugas utama dosen pada beban kerja dosen tentunya menjadi perhatian penting dalam penelitian ini dalam rangka untuk meningkatkan perbaikan dosen/tenaga pendidik dengan menyediakan pusat basis data (data warehouse) yang terintegrasi yang bisa diakses oleh perguruan tinggi yang ada sehingga bisa memperoleh informasi mengenai beban kerja dosen suatu perguruan tinggi secara lengkap, cepat dan akurat untuk mendukung proses evaluasi dan pengambilan sebuah keputusan yang tepat oleh para pemangku kepentingan.

Data warehouse adalah kumpulan data yang berorientasi subyek, terintegrasi, tidak dapat di update, memiliki dimensi waktu, yang digunakan dalam mendukung proses manajemen pengambilan keputusan dan kecerdasan bisnis[2].

Data warehouse merupakan tempat penyimpanan data terpusat, dimana data dari database operasional dan sumber lainnya diintegrasikan, dibersihkan dan diarsipkan untuk mendukung pengambilan keputusan. Data warehouse merupakan sebuah sistem penyimpanan data yang berkapasitas besar, data dikumpulkan dengan menambahkan record baru daripada mengupdate record yang sudah ada dengan informasi baru dan data ini dimanfaatkan untuk proses pengambilan keputusan dan bukan untk kegiatan operasional perusahaan sehari-hari.

[3] Data warehouse merupakan suatu sistem yang mengambil dan menggabungkan data secara periodik dari sumber data (data operasional) menuju ke penyimpanan data dimensional atau penyimpanan data normalisasi [4].

Konsep umum data warehouse dan metadata. Pada dasarnya sistem data warehouse memuat data dari berbagai database operasional, kemudian melakukan pembersihan data, melakukan perubahan atribut data dalam deskripsi atribut yang didefinisikan secara umum untuk kemudian menyimpan ke dalam data warehouse. Bahwasanya metadata dapat digunakan untuk mengekspresikan skema bintang dan pemeliharaan gudang data. User dapat mengekstraksi data siswa dari data warehouse menggunakan tools query.

[5] Pada data warehouse, teknik untuk pemodelan data dinamakan dengan dimensional modelling technicque. Pemodelan dimensioanal merupakan suatu model berbasis pemanggilan yang mendukung akses query volume tinggi.

[2] Dimensional modeling merupakan sebuah teknik yang digunakan untuk mengkonsep dan menggambarkan model data sebagai sebuah kumpulan ukuran yang dijelaskan oleh aspek-aspek yang terjadi dalam bisnis[6].

Pada dimensional model terdapat 2 model dasar yang digunakan yattu star model dan snowflake Model. Dalam penelitian ini, menggunakan star model. Star model merupakan struktur dasar yang digunakan dalam dimensional model yang bentuknya memiliki sebuah tabel pusat yang besar (disebut tabel fakta) dan sekumpulan tabel kecil (disebut tabel dimensi) yang diatur dengan pola yang saling berkaitan dengan tabel fakta. Star scema merupakan sebuah skema relational yang memiliki beberapa tabel fakta yang mereferensi pada satu atau lebih tabel dimensi. Beberapa keuntungan menggunakan star scema adalah memudahkan pengguna dalam memetakan secara langsung antara analisis bisnis entiti, memudahkan pengguna dalam menulis query [6].

ETL singkatan dari Extraction, Transformation, and Loading, adalah proses mengambil dan mengubah data dari sistem sumber dan memasukkannya ke dalam data warehouse [7]. Dalam proses pengambilan data, data harus bersih agar didapat kualitas data yang balk. bahwasanya ETL merupakan proses di dalam pengembangan data warehouse yang melakukan ekstaksi data dari berbagai sumber data. Di dalam proses ETL ada data yang dibersihkan untuk menangani adanya kerangkapan data, inkonsistensi dan integritas data. [8]. ETL merupakan suatu proses yang ada pada data warehouse yang melibatkan pembacaan data dari sumbernya, pembersihan dan penyesuaian format data dan penulisan data tersebut ke dalam ruang penyimpanan untuk digunakan lebih lanjut. Adapun proses dalam ETL meliputi Extraction merupakan suatu proses yang mengidentifikasikan seluruh sumber data yang relevan dan kemudian mengambil data dari sumber-sumber data tersebut. Transform merupakan proses yang memiliki fungsi dalam melakukan perubahan dan integrasi skema data serta struktur yang berbeda ke dalam 
skema dan struktur yang sudah didefinisikan sebelumnya oleh data warehouse. Loading merupakan suatu proses pemindahan data secara fisik dari sistem operasional ke dalam data warehouse.

Skema bintang (star schema) merupakan suatu jenis spesifik dari perancangan database yang dimanfaatkan untuk mendukung proses analitis serta memiliki secara spesifik satuan tabel normalisasi. Yang terdiri tari 2 tabel yaitu tabel fakta dan tabel dimensi. Data fakta merupakan data aktual yang akan dianalisi (data kuantitatif dan transaksi) atribut-atribut dalam tabel fakta sering disebut measure dan biasanya dalam bentuk numerik. Berisi kunci asing dari masing-masing tabel dimensi. Sedangkan tabel dimensi merupakan tabel kecil dan memegang data deskriptif yang mencerminkan dimensi suatu bisnis. [3]

Setiap tabel pada skema bintang harus mempunyai primary key yang terdiri dari satu kolom atau lebih. Fungsi dari primary key tersebut adalah agar setiap record menjadi unik. Primary dari tabel fakta terdiri atas satu atau lebih foreign key [3].

OLAP merupakan teknologi yang digunakan untuk memproses data dalam data warehouse dalam struktur multidimensi sehingga dapat menyediakan jawaban yang tepat untuk query analisis yang komplek [2].

OLAP adalah kombinasi yang dinamis analisis serta gabungan dari data multidimensional dalam jumlah yang besar [4].

Cube merupakan bagian utama dari OLAP yang berisi kumpulan banyak data yang disatukan agar cepat menghasilkan query. Data warehouse dan OLAP menyediakan kunci untuk menyelesaikan masalah yang ada karena pada umumnya mempu menghasilkan data yang terkonsolidasi dan konsisten, berorientasi pada topik tertentu, bersifat historis dan read only.

Data warehouse pada dasarnya bertujuan untuk mempermudah pengaksesan informasi perusahaan. Selain itu data warehouse bisa menyediakan informasi suatu perusahaan secara konsisten, mampu untuk beradaptasi dan tahan terhadap perubahan, dapat mengamankan informasi perusahaan, datawarehouse mampu untuk memberikan dukungan dalam pengambilan sebuah keputusan, data warehouse bisa diterima dan dioperasikan dengan baik oleh pengguna.[2]

Adapun tujuan penelitian ini adalah untuk menghasilkan database yang terintegrasi yang bisa diakses oleh pemangku kepentingan perguruan tinggi, sehingga para pemangku kepentingan bisa memperoleh informasi mengenai beban kerja dosen suatu perguruan tinggi secara lengkap, cepat dan akurat untuk mendukung proses evaluasi dan pengambilan sebuah keputusan strategis yang tepat dengan menyajikan data untuk laporan beban kerja dosen yang dibutuhkan oleh para pemangku kepentingan.

\section{METODOLOGI PENELITIAN}

Berikut ini merupakan metode penelitian yang dilakukan dalam melakukan penelitian ini:

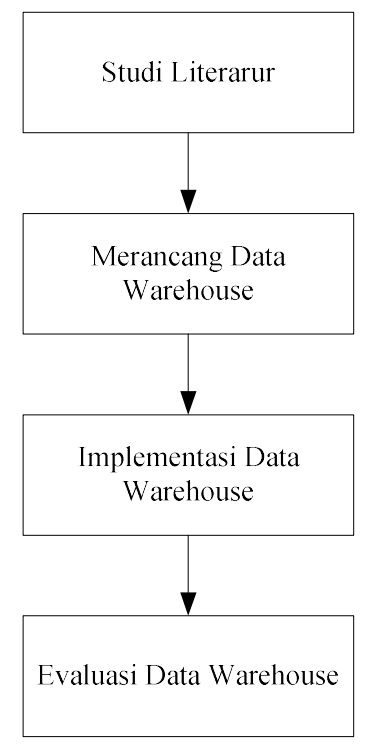

Gambar 1. Metode Penelitian

Tahap awal yang dilakukan dalam penelitian ini adalah melakukan penelusuran literatur yang berkaitan dengan data warehouse yang relefan dengan topik yang penulis ambil. Kemudian penulis melakukan perancang Data Warehouse dengan melakukan identifikasi permasalahan pada sistem yang berjalan. Berdasarkan analisis terhadap permasalahan yang ada, kemudian bisa diketahui kebutuhan sistem yang diusulkan, kemudian dilakukan perancangan data warehouse dengan menggunakan nine step methodology kimball, akan tetapi untuk penelitian ini penulis hanya menggunakan 4 tahapan (Four Step Methodology kimbal) yang ada dalam melakukan 
perancangan data warehouse dari sembilan tahapan yang ada. Selanjutnya dilakukan Implementasi data warehouse ke dalam database. Pada tahapan ini, perancangan data warehouse yang dihasilkan akan diimplementasikan dengan menggunakan DBMS MySQL yang kemudian akan disimulasikan dengan menggunakan interface PhpMyadmin. Dan kemudian dilakukan evaluasi data warehouse. Pada tahapan ini, akan dilakukan evaluasi mengenai rancangan database yang dihasilkan untuk mengetahui sampai sejauh mana kemampuan database data warehouse beban kerja dosen ini bisa menghasilkan informasi strategis beban kerja dosen yang dibutuhkan oleh perguruan tinggi.

\section{HASIL DAN PEMBAHASAN}

Untuk perancangan data warehouse dilakukan dengan menggunakan four step methodology kimball dari sembilan tahapan yang ada. Metode Kimball mengatakan terdapat 9 langkah dalam membangun sebuah data warehouse, yang dikenal dengan nine-step design methodology, jika langkah-langkah dalam nine-step design methodology dilakukan secara sistematis, maka dapat membangun sebuah data warehouse yang baik [13]. 9 langkah tersebut meliputi: Memilih proses, menentukan grain atau sumber dari proses bisnis, mengidentifikasi dan penyesuaian dimensi, memilih fakta, menyimpan perhitungan awal dalam tabel fakta, melihat kembali tabel dimensi, memilih durasi database, menelusuri perubahan dari dimensi, memutuskan prioritas query dan type query, memilih psycal design. Dari sembilan tahapan perancangan yang dilakukan penulis hanya menggunakan 4 tahapan dari sembilan tahapan yang ada yang penjelasannya dijabarkan di bawah ini.

\subsection{Memilih Proses}

Pada tahapan ini, dilakukannya penentuan subjek dari permasalahan yang ada. Pemilihan proses agar bisa memperjelas batasan mengenai data warehouse yang akan dibuat. Adapun proses yang dirancang dalam penelitian ini berdasarkan data yang ada pada beban kerja dosen meliputi proses kegiatan bidang pendidikan, proses kegiatan bidang penelitian, proses kegiatan bidang pengabdian kepada masyarakat, dan proses kegiatan penunjang lainnya. Menentukan grain atau sumber dari proses bisnis.

\subsection{Menentukan Grain Atau Sumber Dari Proses Bisnis}

Penentuan grain dimaksudkan untuk menentukan secara tepat apa yang nantinya akan dipresentasikan oleh record yang ada pada tabel fakta. Berdasarkan hasil analisis terhadap sumber data yang diperoleh. Dimana pemilihan grain dalam merancang data warehouse beban kerja dosen perguruan tinggi antara lain adalah sebagai berikut:

a. Kegiatan bidang pendidikan, analisis meliputi: Analisis jumlah sks seluruh dosen yang melakukan kegiatan bidang pendidikan (yang merupakan kegiatan bidang pendidikan meliputi: melakukan pengajaran, membimbing seminar, membimbing kuliah kerja nyata/praktek kerja nyata/praktek kerja lapangan, membimbing tugas akhir penelitian mahasiswa termasuk membimbing, menjadi penguji pada ujian akhir. membina kegiatan mahasiswa, mengembangkan program kuliah, mengembangkan bahan pengajaran, menyampaikan orasi ilmiah, membimbing akademik dosen yang lebih rendah jabatannya, melaksanakan kegiatan data sering dan pencangkokan akademik dosen, melakukan pengembangan diri untuk meningkatkan kompetensi, dengan periode waktu tertentu (per semester (6 bulan)/ pertahun) pada setiap program studi yang ada.

b. Kegiatan bidang penelitian dan pengembangan ilmu, analisis meliputi: Analisis jumlah sks seluruh dosen yang melakukan kegiatan bidang penelitian dan pengembangan ilmu(meliputi: jumlah karya ilmiah dosen, menghasilkan karya ilmiah, buku ilmiah, menerjemahkan/menyadur buku ilmiah, mengedit/menyunting karya ilmiah, rancangan dan karya teknologi, membuat rancangan dan karya teknologi, rancangan karya seni dosen, membuat rancangan karya seni yang dapat dilihat per periode waktu( per semester (6 bulan)/ pertahun) pada setiap program studi yang ada atau seluruh program studi.

c. Kegiatan pada bidang pengabdian pada masyarakat, analisis meliputi: analisis jumlah sks seluruh dosen yang melakukan kegiatan pengabdian masyarakat ( meliputi: menduduki jabatan pimpinan, melaksanakan pengembangan hasil pendidikan dan penelitian, memberi latihan/penyuluhan/penataran pada masyarakat, memberi pelayanan kepada masyarakat atau kegiatan lain yang menunjang pelaksanaan tugas umum pemerintah dan pembangunan, membuat/menulis karya pengabdian kepada masyarakat yang dapat dilihat per periode waktu( per semester (6 bulan)/ pertahun) pada setiap program studi yang ada atau seluruh program studi yang ada. 
d. Kegiatan penunjang lainnya, analisis meliputi: analisis jumlah sks kegiatan penunjang dosen (meliputi: menjadi anggota dalam suatu panitia/badan pada perguruan tinggi, menjadi anggota panitia/badan pada lembaga pemerintah, menjadi anggota organisasi profesi, mewakili perguruan tinggi/lembaga pemerintah duduk dalam panitia antar lembaga, menjadi anggota delegasi nasional ke pertemuan internasional, analisis berperan serta aktif dalam pertemuan ilmiah, mendapat tanda jasa/penghargaan, menulis buku pelajaran SLTA kebawah, prestasi di bidang olahraga/kesenian/sosial yang dapat dilihat per periode waktu( per semester (6 bulan)/ pertahun) pada setiap program studi yang ada atau seluruh program studi yang ada.

\subsection{Mengindentifikasi dan penyesuaian dimensi}

Pada tahapan ini, dilakukan penyesuaian dimensi yang nantinya akan digunakan dalam perancangan data warehouse diantaranya adalah dimensi dosen, dimensi periode, dimensi KegPendidikan, dimensi KegPengabdian, dimensi KegPKM, Dimensi KegPenunjang. Dimensi dosen meliputi: iddosen(PK), nmdosen, jja, golongan, prodi. Dimensi Periode meliputi:idperiode(PK), tglawal, tglakhir, semester, tahun. Dimensi KegPendidikan meliputi:idkegpend, nmkp, jnskp, buktipenugkp, sksdbkkp, buktidokkk, Skskinerjakp. Dimensi Kegpenenelitian meliputi: idkegpen, nmkpen, jnskpen, buktipen, sksbuktikpen, buktidokkpen, skskinerjakpen. Dimensi KegPengabdian meliputi: idkegpeng, nmkpeng, jnskpeng, buktipenkpeng, sksbkkpeng, buktidokkpeng, skskinerjakpeng. Dimensi KegPenunjang meliputi: idkegpenunj, nmkpenunj, jnskpenunj, buktipenugkpenunj, sksbkkpenunj, buktidokkpenunj, skskinerjakpenung. Untuk penggambarannya dapat dilihat pada gambar 2.

\subsection{Memilih Fakta}

Pada tahapan ini, ditentukan suatu tabel fakta yang berisi fakta-fakta yang bisa digunakan untuk mengetahui informasi apa saja yang ingin dibutuhkan. Adapun tabel fakta tersebut meliputi: iddosen, idperiode, idkegpend, idkegpen, idkegpeng, idkegpenunj, jmIsksKegPen, jumskskegpen, jumskskegpeng, jumskskegpenunj. Untuk penggambaran tabel fakta tersebut dapat dilihat pada gambar 2.

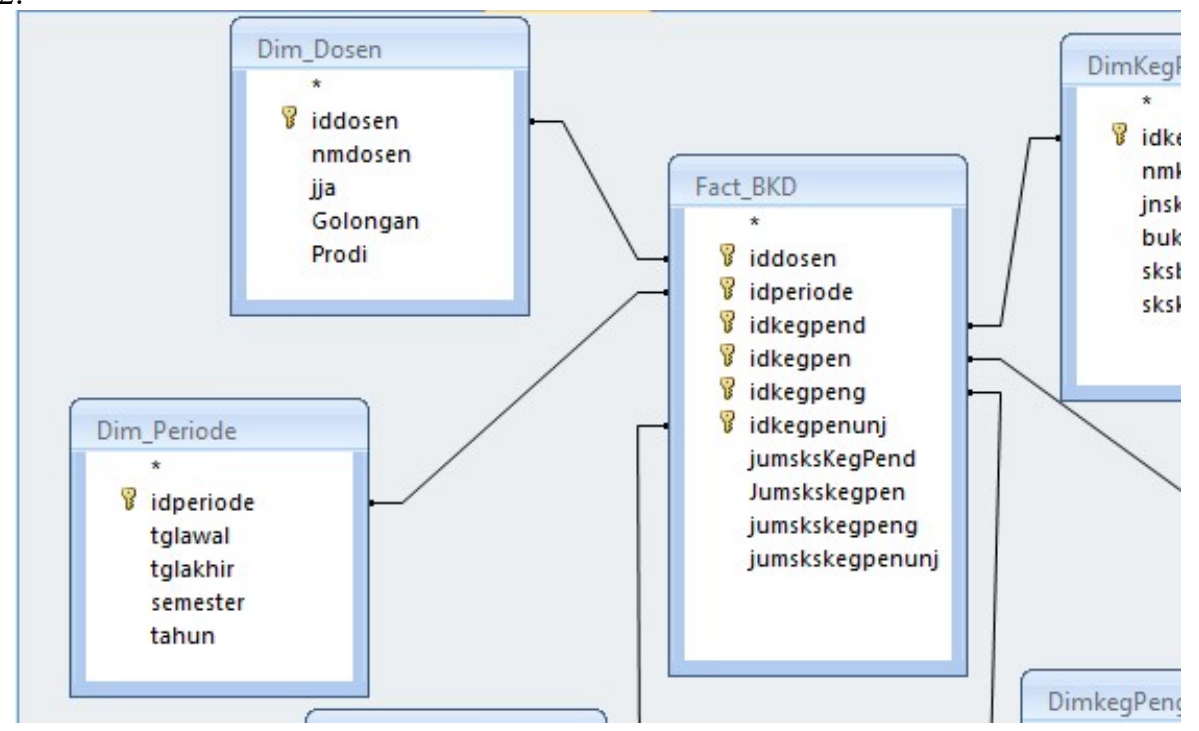

Gambar 2. Skema Bintang Tabel Fakta Dan Tabel Dimensi

Keterangan gambar 2: Perancangan data warehouse menghasilkan 7 tabel dimensi yang meliputi Dim_Dosen(dimensi dosen), Dim_Periode(dimensi Periode/waktu), DimKegPendidikan(Dimensi Kegiatan pendidikan), DimKegPenelitian(dimensi kegiatan penelitian), DimkegPengabdian(dimensi kegiatan pengabdian), DimKegPenunjang(dimensi kegiatan penunjang). Dan terdapat 1 tabel fakta: Fact_BKD.

Berdasarkan hasil perancangan data warehouse diatas kemudian dilakukan implementasi dengan menggunakan DBMS My SQL kemudian dilakukan simulasi dengan menggunakan PhpMyadmin untuk menghasilkan informasi strategis beban kerja dosen diantaranya meliputi Analisis jumlah sks seluruh dosen yang melakukan kegiatan bidang pendidikan berdasarkan program studi dengan periode waktu tertentu(persemester/pertahun, analisis sks seluruh dosen yang melakukan kegiatan penelitian berdasarkan program studi dengan periode waktu tertentu(persemester/pertahun), analisis sks seluruh dosen yang 
melakukan kegiatan pengabdian kepada masyarakat berdasarkan program studi berdasarkan pada periode waktu tertentu(persemester/pertahun), analisis sks seluruh dosen yang melakukan kegiatan penunjang lainnya berdasarkan program studi dengan periode waktu tertentu(persemester/pertahun). Untuk evaluasi saat ini masih sebatas dilakukannya pengujian terhadap database data warehouse yang ada. Yang mana hasil evaluasi data warehouse yang ada dapat dilihat pada tabel 2 di bawah ini:

Tabel 2. Evaluasi terhadap perancangan data warehouse

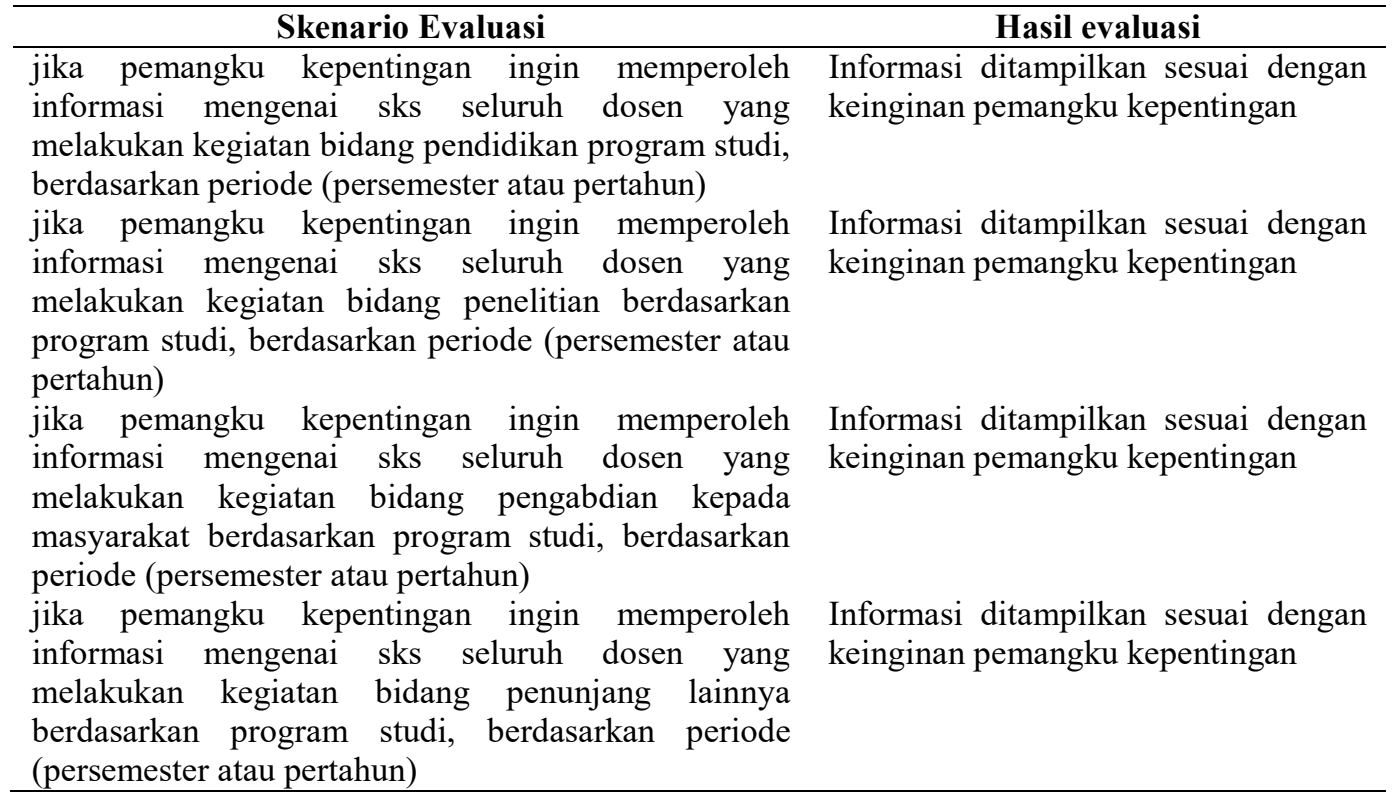

Tabel 2 diatas menjelaskan mengenai hasil valuasi yang dilakukan mengenai data warehouse yang dirancang diantaranya adalah mampu untuk menampilkan informasi mengenai sks seluruh dosen yang melakukan kegiatan bidang pendidikan, bidang penelitian, bidang pengabdian kepada masyarakat, dan kegiatan bidang penunjang lainnya berdasarkan dimensi program studi, berdasarkan dimensi waktu/periode( persemester atau pertahun).

Adapun salah satu bentuk output simulasi analisis perancangan data warehouse beban kerja dosen yang ada dapat dilihat pada tabel 3 di bawah ini:

Tabel 3. Bentuk hasil simulasi analisis data warehouse beban kerja dosen (BKD)

\begin{tabular}{|c|c|c|c|c|c|c|c|c|c|}
\hline $\begin{array}{l}\text { Nama } \\
\text { dosen }\end{array}$ & $\begin{array}{l}\text { Nama } \\
\text { prodi }\end{array}$ & semester & Tahun & $\begin{array}{l}\text { Sks } \\
\text { pendid } \\
\text { ikan }\end{array}$ & $\begin{array}{l}\text { sks } \\
\text { pen } \\
\text { eliti } \\
\text { an }\end{array}$ & $\begin{array}{l}\text { Sks } \\
\text { PK } \\
\text { M }\end{array}$ & $\begin{array}{l}\text { Sks } \\
\text { pen } \\
\text { unj } \\
\text { ang }\end{array}$ & total & keterangan \\
\hline Anisah & $\begin{array}{l}\text { Sistem } \\
\text { informa } \\
\text { si }\end{array}$ & $\begin{array}{l}\text { Gasal } \\
2017 / 2018\end{array}$ & 2017 & 9 & 1,8 & 1 & 2 & 13,8 & memenuhi \\
\hline $\begin{array}{l}\text { Yohanes } \\
\text { S.J }\end{array}$ & $\begin{array}{l}\text { Sistem } \\
\text { informa } \\
\text { si }\end{array}$ & $\begin{array}{l}\text { Gasal } \\
2017 / 2018\end{array}$ & 2017 & 9 & 3,6 & 1 & 2 & 15,6 & memenuhi \\
\hline $\begin{array}{l}\text { Yuyi } \\
\text { Andrika }\end{array}$ & $\begin{array}{l}\text { Sistem } \\
\text { informa } \\
\text { si }\end{array}$ & $\begin{array}{l}\text { Gasal } \\
2017 / 2018\end{array}$ & 2017 & 7 & 1,8 & 1 & 3 & - & $\begin{array}{l}\text { Tidak } \\
\text { memenuhi }\end{array}$ \\
\hline $\begin{array}{l}\text { Elly } \\
\text { Yanuarti }\end{array}$ & $\begin{array}{l}\text { Sistem } \\
\text { informa } \\
\text { si }\end{array}$ & $\begin{array}{l}\text { Gasal } \\
2017 / 2018\end{array}$ & 2017 & 7 & 3,6 & 1 & 3 & 14,6 & memenuhi \\
\hline
\end{tabular}

Tabel 3 diatas merupakan hasil simulasi analisis mengenai data warehouse beban kerja dosen berdasarkan program studi persemester/tahun. Hasil keterangan: (memenuhi) jika total sks gabungan minimal 12 sks dan maksimal 16 sks. Dengan ketentuan. Pendidikan + Penelitian minimal 9 sks, pengabdian + penunjang minimal 3 sks sesuai dengan syarat UU. Selain itu maka keterangannya (tidak memenuhi). Untuk proses perhitungan beban sks masing-masing kegiatan, digunakan rubrik BKD. 


\section{KESIMPULAN}

Kesimpulan yang hasilkan berdasarkan pembahasan yang telah dilakukan adalah Database (data warehouse) Beban Kerja Dosen yang dirancang terdiri dari tabel dimensi yang meliputi tabel dimensi dosen, tabel dimensi periode, tabel dimensi Kegiatan pendidikan, dimensi kegiatan penelitian, dimensi kegiatan pengabdian kepada masyarakat, dimensi kegiatan penunjang. Selain itu terdapat tabel fakta yaitu: fact_BKD. Sehingga berdasarkan tabel yang telah dirancang tersebut dapat memberikan informasi startegis kepada pemangku kepentingan mengenai beban kerja dosen pertahun/persemester Perguruan Tinggi secara lengkap, cepat dan akurat.

\section{DAFTAR PUSTAKA}

[1] Djoko Kustono. HM, Yanuar Syah Haroen., et al. (2012). Buku Pedoman BKD: Direktorat Jendral Pendidikan Tinggi Kementrian Pendidikan Nasional

[2] Mohammad Yazdi Pusadan, S.Kom., M.Eng. (2013). Rancangan Bangun Data Warehouse: Graha Ilmu.

[3] Indrajani, S.Kom., MM. (2014). Prinsip Pengantar sistem basis data case study All in One: Elex Media Komputindo.

[4] Connolly, Thomas. Begg, Carolyn. (2010). Database Systems: A Practical Approach to Design Implementation and Management. America: Pearson

[5] Than Than Wai. 2009. "Metadata Based Student Data Extraction from Universities Data Warehouse". International Conference on Signal Processing Systems.

[6] Humasak Simanjuntak., et al. 2012. "Transformator Entity Relationship Model Ke Star Scema", konferansi Nasional ICT-M Ploteknik Telkom (KNIP).

[7] Rainardi, V. (2008). Building a Data Warehouse with Examples in SQL Server. Apress. New York.

[8] Rahmadi Wijaya, dkk. 2015. "An Overview and Implementation of Extraction-TransformationLoading (ETL) Process in Data Warehouse. International Conference on Information and Communication Technology (ICoICT).

[9] I Gede Made Karma, dkk .2015. Pengembangan Sistem Informasi Beban Kerja Dosen (Bkd) Untuk Pelaporan Pelaksanaan Tridharma Perguruan Tinggi. Seminar Nasional dan Pertemuan Peneliti (Senapati).

[10] Joseph George, et al, 2015. "Data Warehouse Design Considerations for a Healthcare Business Intelligence System". Proceedings of the World Congress on Engineering. Vol WCE 2015, July 1 - 3, London, U.K.

[11] Ganda Wijaya. 2017. "Perancangan Data Warehouse Nilai Mahasiswa Dengan Kimball Nine-Step Methodology", Jurnal Informatika, Vol.4 No.1, April 2017: 1-11.

[12] Reza Rahutomo, Raissa Amanda Putri., et al.2018. "Building Datawarehouse for Educational Institutions in 9 Steps", The 1st 2018 INAPR International Conference, Jakarta-Indonesia.

[13] Kimball, R., \& Ross, M. (2010), The Kimball Group Reader: Rentlessly Practical Tools for Data Warehousing and Business Intelligence. Indianapolis: Wiley Publishing, Inc.

[14] Abba Suganda Girsang, Sani Muhamad Isa, Bambang Susilo, MaxLian, Danang Satya, Salman Al Fariz, Dudi Ramdani., 2017. Decision Support System Using Data Warehouse

for Hotel Reservation System. International Conference on Sustainable Information Engineering and Technology (SIET).

[15] Indrajani Sutedja, Pandi Yudha, Nurul Khotimah, Claresta Vasthi., 2017. Building A Data Warehouse to support Active Student Management: Analysis and Design for Hotel Reservation System. International Conference on Information Management and Technology (ICIMTech)

[16] Yova Ruldeviyani, Bofandra Mohammad. 2016. "Design and Implementation of Merchant Acquirer Data Warehouse at PT. XYZ". IWBIS

[17] Fajar Zaki Al Faris, Suharjito., et al. 2018. "Development of Data Warehouse to Improve Services in IT Services Company". International Conference on Information Management and Technology (ICIMTech) 